\title{
Medical perception of stroke care conditions in Brazil
}

\author{
Percepção médica sobre as condições para atendimento do AVC no Brasil \\ Vivian Dias Baptista Gagliardi1,2, Marcel Simis³, Hideraldo Luiz Souza Cabeça ${ }^{4}$, Rubens José Gagliardi1,5
}

\begin{abstract}
Stroke is currently the second leading cause of death in Brazil. Neurologists' reports on the absence of adequate resources for stroke care are frequent; however, there are no objective data on this perception. Objective: To assess the perception of neurologists of stroke care conditions in Brazil. Methods: Neurologists from all over Brazil were surveyed by means of an anonymous questionnaire about the main shortcomings in stroke care, focusing particularly on physical structure and infrastructure (diagnostic methods, patient transport, availability of beds, multi-professional team). Results: The main shortcomings are indicated: the worst conditions, among all items surveyed, were found in the public sector. In the private sector, conditions were better. Conclusions: Care conditions are worse in the public sector with regard to both infrastructure and human resources. Future public health policies for the prevention and treatment of stroke should be formulated, taking into consideration neurologists' perceptions.
\end{abstract}

Keywords: stroke; surveys and questionnaires; medical care.

\section{RESUMO}

O acidente vascular cerebral é atualmente a segunda causa de morte no Brasil. São frequentes os relatos de médicos neurologistas sobre a ausência de recursos adequados para o atendimento do AVC, no entanto, não existem dados objetivos sobre essa percepção. Objetivo: Analisar a percepção de médicos neurologistas sobre as condições para o atendimento de AVC no Brasil. Métodos: Neste estudo foi realizada pesquisa por questionário anônimo com médicos neurologistas de todo o Brasil, perguntando-se as principais deficiências para o atendimento, com foco na estrutura física, infraestrutura (métodos diagnósticos, transporte do doente, disponibilidade de leitos, equipe multiprofissional). Resultados: As principais deficiências são apontadas; no setor público notou-se as piores condições, em todos os itens pesquisados. No setor privado, as condições são melhores. Conclusões: As condições de atendimento são piores no setor público, tanto de infraestrutura quanto de recursos humanos. Futuras políticas de saúde pública para prevenção e tratamento do AVC deveriam ser elaboradas levando em consideração a percepção do neurologista.

Palavra-chave: acidente vascular cerebral; inquéritos e questionários; cuidados médicos.

Stroke is an increasingly-important cause of death and disability in low- and middle-income countries ${ }^{1}$. This fact is largely driven by demographic changes (increase and aging of the population) and reinforced by an increase in the prevalence of the main modifiable risk factors, especially among the urban population ${ }^{1}$. In Brazil, stroke is currently the second leading cause of death and disabling sequelae $\mathrm{e}^{2.3}$.

Stroke, despite its severity, is a disease with good potential for prevention and should be treated as an emergency after its onset ${ }^{4}$. Patients often do not readily recognize the signs of a stroke, either in Brazil ${ }^{5}$ or in developed countries, like
Australia $^{6}$ and the United States of America ${ }^{7}$, delaying the call for immediate medical care and thereby reducing the therapeutic success.

In the face of the scenario where the population lacks information, which interferes with a more effective treatment, efforts have been made to raise awareness about this problem in order to improve primary and secondary prevention, as well as to advise on the possible benefits of immediately seeking out a service specializing in cases with signs suggestive of stroke. In the United States of America, Reeves et al. ${ }^{8}$ demonstrated a significant improvement in public awareness

\footnotetext{
${ }^{1}$ Irmandade da Santa Casa de São Paulo, Disciplina de Neurologia, São Paulo SP, Brasil;

${ }^{2}$ Universidade Federal de São Paulo, Departamento de Neurologia e Neurocirurgia, São Paulo SP, Brasil;

${ }^{3}$ Universidade de São Paulo, Faculdade de Medicina, Hospital das Clínicas, Instituto de Medicina Física e Reabilitação, São Paulo SP, Brasil;

${ }^{4}$ Conselho Federal de Medicina, Câmera Técnica, Brasília DF, Brasil;

${ }^{5}$ Faculdade de Ciências Médicas da Santa Casa de São Paulo, São Paulo SP, Brasil.
}

Correspondence: Rubens Jose Gagliardi; Rua Cesario Motta Jr, 112; 01221-020

São Paulo SP, Brasil; E-mail: rubensjg@apm.org.br

Conflict of interest: There is no conflict of interest to declare.

Received 28 June 2017; Accepted 19 September 2017. 
among the population in the state of Michigan after a continuous five-year public education campaign on the issue. Some systematic reviews ${ }^{9,10}$ have attempted to define what kind of educational approach yields better results in improving the population's knowledge in the United States of America.

In Brazil, policies for stroke have had a boost since 2008, when the Brazilian Ministry of Health included the disease in an emergency project, creating the "Projeto Nacional de $A V C^{\prime \prime 11}$ (the National Stroke Project), aimed at setting up a multiprofessional task force to increase the scientific support needed for improving education, treatment and scientific research on the subject in the country. The educational efforts to improve this outlook included the "World Stroke Day" in Brazil, coordinated by the Brazilian Academy of Neurology (Academia Brasileira de Neurologia) and the Brazilian Society of Cerebrovascular Diseases (Sociedade Brasileira de Doenças Cerebrovasculares) with the support of the Brazilian Ministry of Health, which received the award for the best stroke awareness campaign from the World Stroke Organization in 2012, 2013, and $2014^{12}$.

Despite the work conducted in Brazil on education targeted at both laypeople and healthcare professionals ${ }^{13}$ and aimed at increasing the effectiveness of prevention and treatment of stroke, there are still no studies on the working conditions faced in this type of care. It is, therefore, necessary to assess the human resources and infrastructure available in Brazil, both of which may have implications for the optimal treatment of stroke.

This study aims to give an overview of the perception of neurologists of the current conditions of stroke care in Brazil and collaborate on improvement of policies for the prevention and treatment of stroke.

\section{METHODS}

E-mails were sent to all neurologists registered with the Brazilian Academy of Neurology (Academia Brasileira de Neurologia) (a total of 1,732) with an open invitation to voluntarily participate in a questionnaire on personal perceptions of stroke treatment conditions in their clinical practice. Students and non-neurologists were excluded from the research. Of the total, 384 neurologists agreed to participate in the survey.

An anonymous and confidential questionnaire was administered, with 14 "multiple-choice" questions related to neurological care provided by public services, private services, and private health insurance organizations. There were three demographic questions, and one open question for suggestions (Appendix). The estimated time to complete the questionnaire was seven minutes.

The questionnaire was open for responses from October 17 to November 30, 2015. It was designed on the online questionnaire platform provided by the Survey Monkey website, with confidentiality of information being guaranteed.

\section{RESULTS}

The first question referred to the workplace; most neurologists work in the public service $(76.4 \%)$, followed by private healthcare $(53.9 \%)$ and private health insurance organizations (48.4\%). Many neurologists work at more than one location.

The survey inquired about the conditions under which health care was provided, and the structure of the service where professionals worked, by using an open multiple-choice question. The results are shown in the Table and Figure 1.

Neurologists were also questioned about which aspects of human resources should be improved for outpatient care, aiming at the prevention and treatment of stroke, with possible ratings ranging from 1 to 5 ( 1 being the highest priority for improvement, and 5 being the lowest priority). Figure 2 shows the mean ratings for each item, with a comparison of the three professional fields of practice.

Infrastructure aspects were assessed by ratings from 1 to 5, shown in Figures 3 and 4.

With respect to the length of time since graduation from medical school, the analysis of the participants' epidemiological profile showed $20.6 \%$ with less than five years, $29.2 \%$ between five and 10 years, $23.4 \%$ from 11 to 20 years, $13.9 \%$ from 21 to 30 years, and $12.8 \%$ with over 30 years of neurological practice. Seventy-eight percent of these neurologists deal with neurological emergencies. Twenty-five Brazilian states were represented.

\section{DISCUSSION}

Multiple efforts have been made to improve the education of patients and professionals on stroke care in Brazil ${ }^{11,12}$, but we have little information about the current situation in which the neurologist operates within the purview of infrastructure and human resources.

This study sought to quantify the medical conditions of stroke care in Brazil by recording the opinion of neurologists directly involved with the management of these patients. The studies with records of personal opinions in a large population attract significant interest as they give one an overview of the current situation, point out shortcomings and contribute to establishing public policies aimed at improving the medical service provided. This study involved significant collaboration with the neurologists who answered the call from the Brazilian Academy of Neurology; questionnaires were sent to 1,732 neurologists from all over Brazil, 384 of whom responded, coming from 25 different states. The response 
Table. Structural features of the service premises (items I-XIV), according to the professional's field of practice.

\begin{tabular}{|c|c|c|c|c|c|c|}
\hline \multirow[t]{2}{*}{ Variable } & \multicolumn{2}{|c|}{ Public Service } & \multicolumn{2}{|c|}{ Private Service } & \multicolumn{2}{|c|}{$\begin{array}{l}\text { Private Health Insurance } \\
\text { Organizations }\end{array}$} \\
\hline & $\%$ & $n$ & $\%$ & $\mathrm{n}$ & $\%$ & $\mathrm{n}$ \\
\hline $\begin{array}{l}\text { I. Support from the rescue service "SAMU" within } 10 \\
\text { minutes (Portuguese acronym for "Serviço de Atendimento } \\
\text { Móvel de Urgência", i.e. Emergency Mobile Care Service) }\end{array}$ & 28.1 & 82 & 37.8 & 87 & 37.5 & 69 \\
\hline II. Screening for immediately identifying stroke patients & 49.7 & 145 & 71.7 & 165 & 64.1 & 118 \\
\hline $\begin{array}{l}\text { III. Trained multi-professional teams to support diagnosis } \\
\text { and treatment }\end{array}$ & 47.3 & 138 & 62.2 & 143 & 53.8 & 99 \\
\hline IV. Sufficient medical teams to meet the demand & 41.4 & 121 & 65.2 & 150 & 60.9 & 112 \\
\hline V. Access to CT within 15 minutes & 58.2 & 170 & 78.7 & 181 & 75.5 & 139 \\
\hline VI. Access to MRI within 15 minutes & 5.5 & 16 & 39.1 & 90 & 32.1 & 59 \\
\hline VII. Access to laboratory tests within 15 minutes & 41.1 & 120 & 68.7 & 158 & 62.0 & 114 \\
\hline VIII. ICU/emergency beds for the use of thrombolytic drugs & 49.0 & 143 & 77.4 & 178 & 73.9 & 136 \\
\hline IX. Availability of thrombolytic drugs & 68.2 & 199 & 78.3 & 180 & 71.7 & 132 \\
\hline X. Installations and facilities able to absorb the demand & 22.3 & 65 & 67.0 & 154 & 64.7 & 119 \\
\hline $\begin{array}{l}\text { XI. Number of inpatient beds in sufficient quantities to } \\
\text { meet the demand }\end{array}$ & 15.4 & 45 & 65.2 & 150 & 61.4 & 113 \\
\hline XII. Offer of training to the medical team & 34.9 & 102 & 46.1 & 106 & 36.4 & 67 \\
\hline $\begin{array}{l}\text { XIII. Offer of training to other health professionals } \\
\text { (supporting team) }\end{array}$ & 29.1 & 85 & 44.3 & 102 & 36.4 & 67 \\
\hline XIV. None of the above & 18.8 & 55 & 12.2 & 28 & 12.5 & 23 \\
\hline Questions answered & & 292 & & 230 & & 184 \\
\hline Questions left blank & & 92 & & 154 & & 200 \\
\hline
\end{tabular}

$\mathrm{n}$ : number of responses.

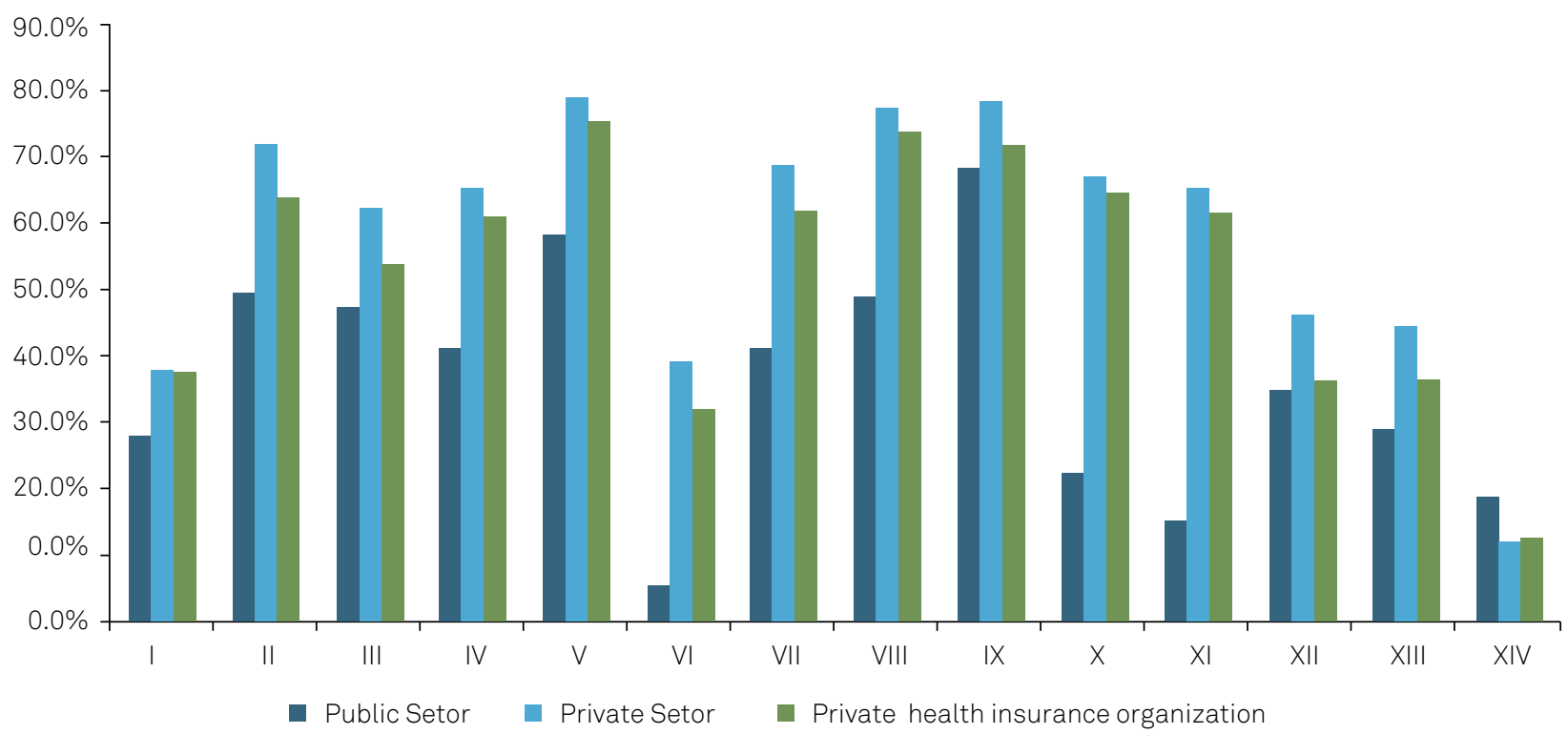

Figure 1. Proportion of responses by professional field of practice, according to items numbered I to XIV as detailed in the Table. Questions 2,6, and 10: Considering the structure (physical and human resources) needed for acute stroke care (emergency), the public service/private service/private health insurance organization in which you work has the following items.

rate corresponds to $22.17 \%$ of the sample, which is considered suitable for this type of analysis.

Most of the participants work in the public service; the number of participants working in the private sector or private health insurance organizations was similar. Seventyeight percent of the total sample deal with neurological emergencies. With reference to the length of time dedicated to specialized training, there was significant participation of all groups. Most questionnaires were answered by physicians in southeastern Brazil (states of São Paulo, Minas Gerais, and Rio de Janeiro) and southern Brazil (states of Paraná and Rio Grande do Sul), which have the highest concentrations of neurologists.

With respect to the human and physical resources available to professionals for stroke care, all resources inquired about were observed to be present in smaller amounts in 


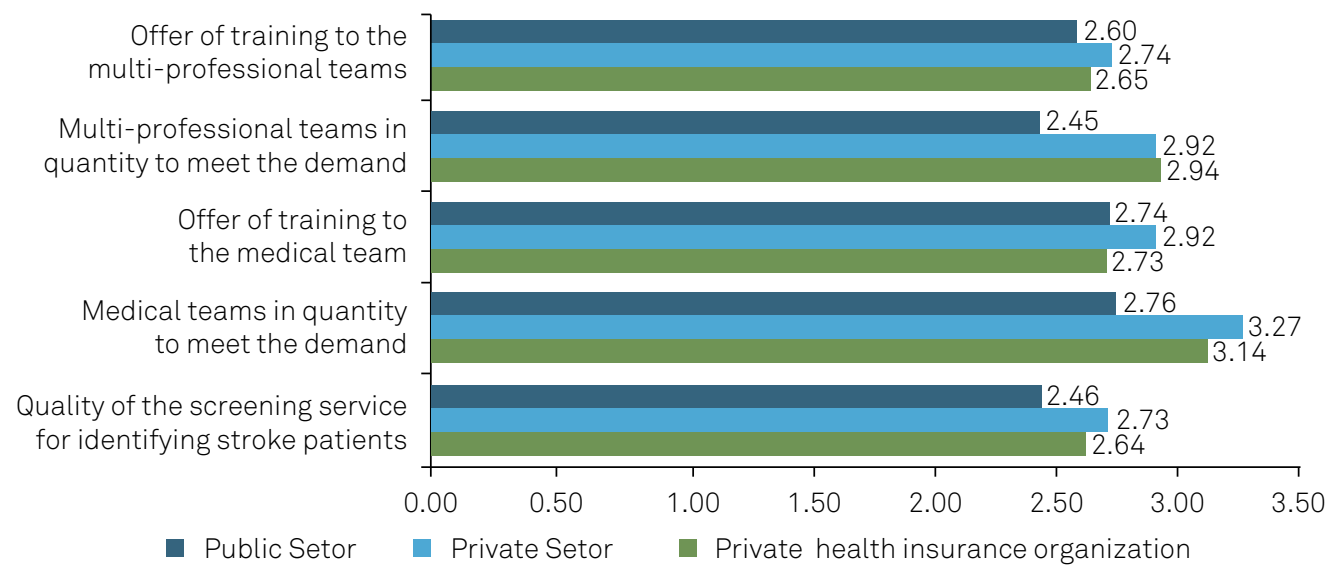

Figure 2. Aspects of human resource that should be improved, by field of practice; mean ratings given for each aspect, with 1 being the highest priority for improvement and 5, the lowest priority.Questions 3, 7, and 11: Considering the past six weeks in the public service/private service/private health insurance organization in which you work, which among the following aspects of human resources should be improved in outpatient care for stroke prevention and treatment?

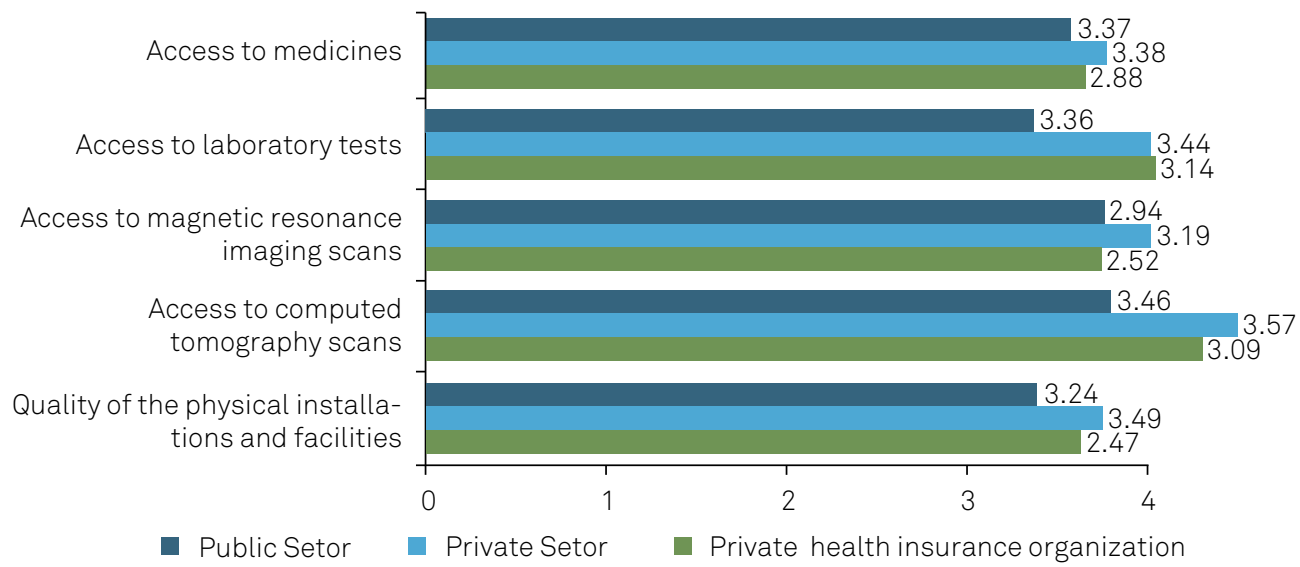

Figure 3. Structural aspects that should be improved, by field of practice; mean ratings given for each aspect, with 1 being the highest priority for improvement and 5, the lowest priority. Questions 4, 8 and 12: Considering the past six weeks in the public service/private service/private health insurance organization in which you work, which among the following structural aspects should be improved in outpatient care for stroke prevention and treatment?

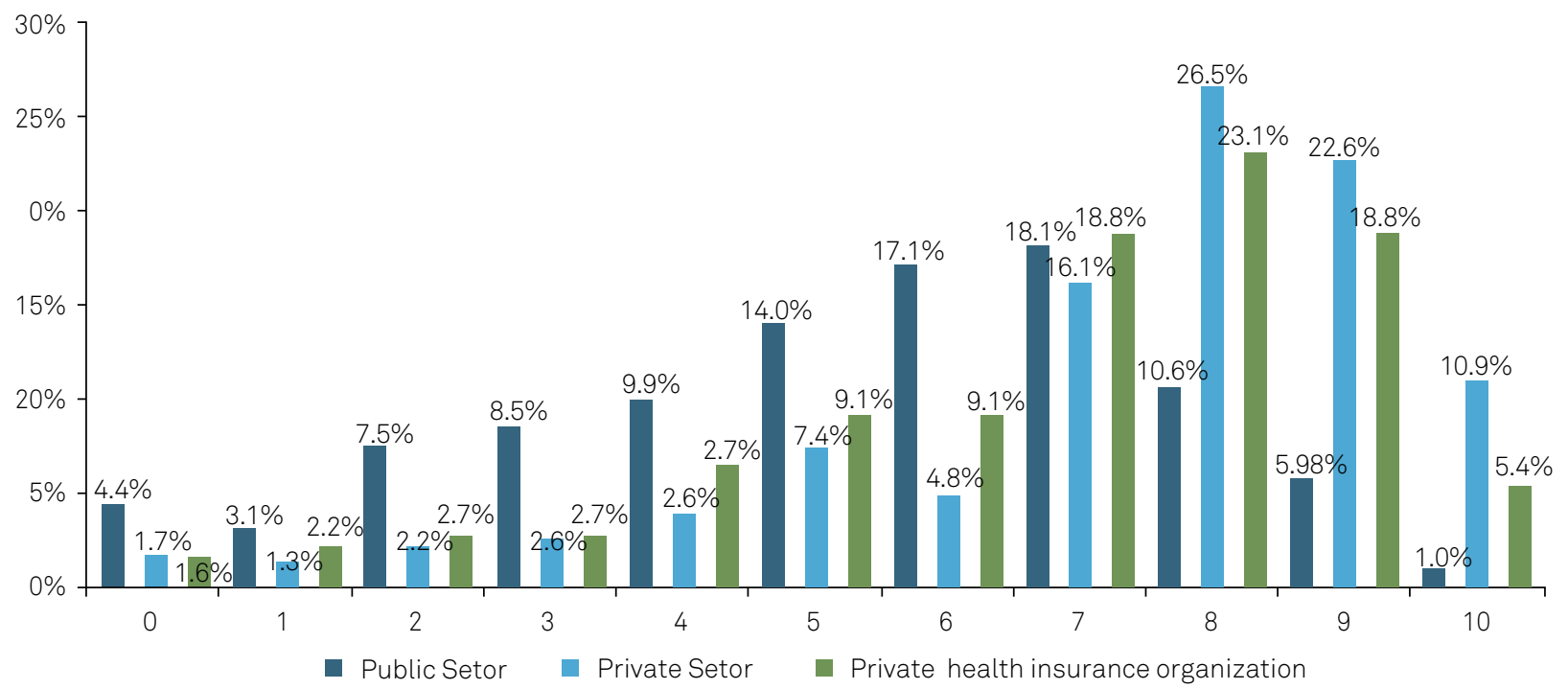

Figure 4. Assessment of the infrastructure offered to stroke care and treatment, according to the place of professional practice, rated from 0 to 10 (with 0 being the worst and 10 the best). Questions 5, 9 and 13: With regard to the outpatient care for the prevention and treatment of stroke that you have provided in the public service/private service/private health insurance organization in the past six weeks and taking into consideration the infrastructure (installations, number and quality of equipment, access to beds, access to medicines and supplies), on a scale of 0 to 10 ( 0 being the worst rating and 10 , the best rating), what rating do you give to your service in general? 
the public sector. The availability of resources in the private sector and private health insurance organizations is similar, being slightly higher in the private sector. The most significant differences (greater than 20\%) were found in the following items:

1) Sufficient medical teams to meet the demand;

2) Access to CT within 15 minutes;

3) Access to MRI within 15 minutes;

4) ICU/emergency beds for the use of thrombolytic drugs;

5) Installations and facilities compatible with absorbing the demand;

6) Number of inpatient beds in sufficient quantities to meet the demand;

7) Offer of training for other health professionals.

We thus observed that the public sector's shortage is greater concerning infrastructure, with respect to both the access to imaging studies necessary for the service and the allocation of beds to these patients. Furthermore, it was found that there are fewer medical teams than required to meet the needs of these patients and less available training for other professionals who participate in the medical care. It is also interesting to note that the presence of rescue support for the patient within 10 minutes was small in the three fields of practice (reaching the highest percentage, $37.8 \%$, in the private sector), as was the access to MRI within 15 minutes (the highest percentage, $39.1 \%$, was observed in the private sector), thus indicating the need for an intervention to improve these items, not only in the public sector.

With respect to the ratings for human resources and improvement priority (Figure 2), it was found that, in the public service, greater priority is given to the need for sufficient multiprofessional teams to meet the demand, followed by quality in the screening service for identifying patients with stroke. The private healthcare sector and private health insurance organizations listed their priorities for improvements as better quality of the screening service for identifying patients with stroke and available training for multiprofessional teams. These data show the need for education programs targeted for practitioners of other professions, especially those who conduct the screening of patients, which would benefit the three medical care sectors.

The structural features (Figure 3) that would be a priority for improvement in the public sector are the quality of the physical installations and facilities and access to MRI scans. Interestingly, these were the same items found to be a priority for improvement in private health insurance organizations (with the highest priority being the availability of access to MRI). Those working in the private sector described their major priorities as the access to MRI and medicines. The availability of access to MRI is hindered by the high cost of this apparatus, which seems to be important in the three fields of practice.

The general perception of the infrastructure available for treatment, as assessed by ratings from 0 to 10 (Figure 4), also shows a tendency towards worse ratings for the public sector (with $49 \%$ of ratings ranging between 5-7 points). The private sector and private health insurance organizations obtained better ratings, the former having performed better than the latter (private sector, $65.2 \%$ of ratings ranging between 7 and 9; private health insurance organizations, $60.7 \%$ of ratings ranging between 7 and 9). The need to request better infrastructure conditions from the relevant authorities for the public sector in order to improve stroke care becomes apparent.

In conclusion, this study shows that in the working reality of Brazilian neurologists, the public sector has the largest deficits, both in infrastructure resources and human resources (sufficient professionals for medical care and the training of multiprofessional teams). Ways to promote improvements, both structural and in human resources should, therefore, be explored with the relevant authorities in the public health sector.

\section{Acknowledgments}

To Dr Lidia Moura, from Harvard School, and to the journalist Paulo Henrique de Souza from the Federal Council of Medicine (Conselho Federal de Medicina), for their collaboration in the preparation of the questionnaire and revision of materials.

\section{References}

1. Bonita R, Beaglehole R. Stroke prevention in poor countries: time for action. Stroke. 2007;38(11):2871-2. https://doi.org/10.1161/STROKEAHA.107.504589

2. Lotufo PA, Goulart AC, Fernandes TG, Benseñor IM. A reappraisal of stroke mortality trends in Brazil (1979-2009). Int J Stroke. 2013;8(3):155-63. https://doi.org/10.1111/j.1747-4949.2011.00757.x

3. Datasus. Centro Tecnológico de Informação e Informática do SUS. 2015 [cited 2015 Dec]. Available from: http://www.datasus.gov.br

4. Martins SC, Freitas GR, Pontes-Neto OM, Pieri A, Moro CH, Jesus PA et al. Guidelines for acute ischemic stroke treatment. Part II: stroke treatment. Arq. Neuropsiquiatr. 2012;70(11):885-93. https://doi.org/10.1590/S0004-282X2012001100012
5. Pontes-Neto OM, Silva GS, Feitosa MR, Figueiredo NL, Fiorot Junior JA, Rocha TN et al. Stroke awareness in Brazil: alarming results in a community-based study. Stroke. 2008;39(2):292-6. https://doi.org/10.1161/STROKEAHA.107.493908

6. Sug Yoon S, Heller RF, Levi C, Wiggers J, Fitzgerald PE. Knowledge of stroke risk factors, warning symptoms, and treatment among an Australian urban population. Stroke. 2001;32(8):1926-30. https://doi.org/10.1161/01.STR.32.8.1926

7. Reeves MJ, Hogan JG, Rafferty AP. Knowledge of stroke risk factors and warning signs among Michigan adults. Neurology. 2002;59(10):1547-52. https://doi.org/10.1212/01.WNL.0000031796.52748.A5 
Reeves MJ, Rafferty AP, Aranha AA, Theisen V. Changes in knowledge of stroke risk factors and warning signs among Michigan adults. Cerebrovasc Dis. 2008;25(5):385-91. https://doi.org/10.1159/000121338

9. Lecouturier J, Rodgers H, Murtagh MJ, White M, Ford GA, Thomson $R G$. Systematic review of mass media interventions designed to improve public recognition of stroke symptoms, emergency response and early treatment. BMC Public Health. 2010;10(1):784. https://doi.org/10.1186/1471-2458-10-784

10. Payne GH, Fang J, Fogle CC, Oser CS, Wigand DA, Theisen V et et al. Stroke awareness: surveillance, educational campaigns, and public health practice.J Public Health Manag Pract. 2010;16(4):345-58. https://doi.org/10.1097/PHH.0b013e3181c8cb79
11. Martins SC, Pontes-Neto OM, Alves CV. Past, present, and future of stroke in middle-income countries: the Brazilian experience. Int J Stroke. 2013;8 suppl A 100:106-11. Https://doi.org/10.1111/ijs.12062

12. Pontes-Neto OM. Stroke awareness in Brazil: what information about stroke is essential? Arq. Neuropsiquiatr. 2014;72(12):909-10. https://doi.org/10.1590/0004-282X20140197

13. Fernandes PT, Avelar WM, Mory SB, Hansen R, Li LM. Perception and attitude towards stroke by professionals of emergency medical service in an urban city in southeastern Brazil.J Stroke Cerebrovasc Dis. 2009;18(3):195-7. https://doi.org/10.1016/j.jstrokecerebrovasdis.2008.09.007 